Open Access

\title{
De novo deletions and duplications of $17 q 25.3$ cause susceptibility to cardiovascular malformations
}

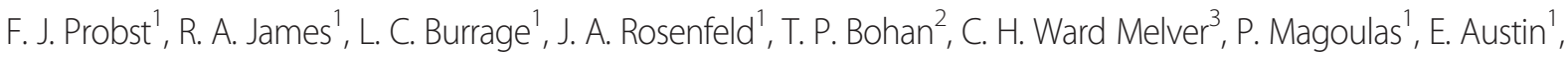

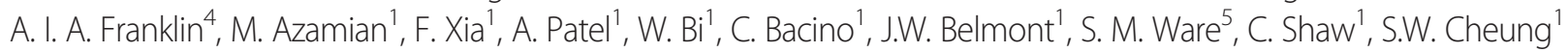 \\ and S. R. Lalani $i^{*}$
}

\begin{abstract}
Background: Genomic disorders resulting from deletion or duplication of genomic segments are known to be an important cause of cardiovascular malformations (CVMs). In our previous study, we identified a unique individual with a de novo 17q25.3 deletion from a study of 714 individuals with CVM.

Methods: To understand the contribution of this locus to cardiac malformations, we reviewed the data on 60,000 samples submitted for array comparative genomic hybridization (CGH) studies to Medical Genetics Laboratories at Baylor College of Medicine, and ascertained seven individuals with segmental aneusomy of 17q25. We validated our findings by studying another individual with a de novo submicroscopic deletion of this region from Cytogenetics Laboratory at Cincinnati Children's Hospital. Using bioinformatic analyses including protein-protein interaction network, human tissue expression patterns, haploinsufficiency scores, and other annotation systems, including a training set of 251 genes known to be linked to human cardiac disease, we constructed a pathogenicity score for cardiac phenotype for each of the 57 genes within the terminal $2.0 \mathrm{Mb}$ of 17q25.3.
\end{abstract}

Results: We found relatively high penetrance of cardiovascular defects ( $60 \%)$ with five deletions and three duplications, observed in eight unrelated individuals. Distinct cardiac phenotypes were present in four of these subjects with non-recurrent de novo deletions (range $0.08 \mathrm{Mb}-1.4 \mathrm{Mb}$ ) in the subtelomeric region of 17q25.3. These included coarctation of the aorta (COA), total anomalous pulmonary venous return (TAPVR), ventricular septal defect (VSD) and atrial septal defect (ASD). Amongst the three individuals with variable size duplications of this region, one had patent ductus arteriosus (PDA) at 8 months of age.

Conclusion: The distinct cardiac lesions observed in the affected patients and the bioinformatics analyses suggest that multiple genes may be plausible drivers of the cardiac phenotype within this gene-rich critical interval of 17q25.3.

Keywords: 17q25 Deletion, Copy number variations, Congenital heart defects, Intellectual disability

\section{Background}

Several rare recurrent DNA copy number variations (CNVs) and novel genomic loci have been implicated in congenital cardiac malformations, categorically establishing the importance of CNVs in clinical evaluation of individuals with CVM [1-5]. It is estimated that genomic disorders account for approximately $10 \%$ of all CVM

\footnotetext{
* Correspondence: seemal@bcm.tmc.edu

'Department of Molecular and Human Genetics, Baylor College of Medicine, One Baylor Plaza, MS BCM225, Houston, TX, USA

Full list of author information is available at the end of the article
}

cases. While 22q11.2 deletion (MIM 188400) remains the most common genomic disorder responsible for CVM, other less frequent, but important, contributors include 1 p36 monosomy (MIM 607872), Williams-Beuren syndrome (7q11.2 deletion; MIM 194050), 8p23.1 deletion encompassing GATA4 and SOX7, 9q34 deletion involving EHMT1 (MIM 610253), and 17q21.31 microdeletion including KANSL1 (MIM 610443). These genomic disorders are known to be associated with relatively high penetrance of CVM, often affecting dosage sensitive genes within the 
deleted intervals. The recurrent 1q21.1 distal deletion (Class I deletion; MIM 612474) encompassing GJA5 is also associated with CVM [6] with incomplete penetrance (10-25\% of cases). The reciprocal duplication 1q21.1 (MIM 612475), on the other hand is strongly linked to tetralogy of Fallot (TOF) in several studies $[2,7,8]$. The recurrent 22q11.2 distal deletion is yet another genomic disorder linked to cardiac malformations in numerous reports $[9,10]$. In our previous study of over 700 individuals with syndromic CVMs, we identified a de novo submicroscopic 17q25.3 loss in an affected individual, which was not observed in over 2,800 controls [1]. Other than this unique case, pure subtelomeric deletions confined to $17 q 25.3$ have not been reported. Pure 17q25.3 submicroscopic copy number gains are also infrequent, and have been observed in association with distal arthrogryposis, craniofacial dysmorphism and atrial septal defect (ASD) [11]; intellectual disability [12, 13]; and with severe microcephaly with concurrent mutation in WDR62 [14]. While several reports of unbalanced rearrangements of terminal 17q have been described with concomitant monosomy or trisomy of other autosomes and X chromosome [15-21], pure subtelomeric rearrangements of $17 \mathrm{q} 25.3$ unarguably remain inadequately delineated amongst the group of subtelomeric disorders. Here we report a case series of eight individuals, five with pure non-recurrent submicroscopic $17 \mathrm{q} 25.3$ deletions and three with 17q25 duplication. We provide a detailed phenotypic characterization associated with genomic rearrangement of this region, and show a penetrance of $\sim 60 \%$ for CVMs in this group. This study identifies a novel genomic locus responsible for congenital cardiac malformations and identifies potential critical genes within the terminal region of 17q25.3 related to cardiac morphogenesis.

\section{Subjects and methods Human subjects}

Patients were ascertained from screening of 60,000 samples submitted for clinical chromosomal microarray analyses completed at the Medical Genetics Laboratories (MGL) of Baylor College of Medicine (BCM). The study was performed in accordance with the institutional guidelines for human research with approval by the Institutional Review Board of Baylor College of Medicine and Cincinnati Children's Hospital Medical Center. The novel genomic loss of subject 1 was previously reported in the literature [1]. Photographs were obtained for publication after appropriate parental consents.

\section{Cytogenetic, molecular cytogenetic and molecular analysis} DNA was extracted from whole blood by the Puregene DNA Blood Kit (Gentra) according to the manufacturer's instructions. The procedures for DNA digestion, labeling, and hybridization for the oligo arrays were performed according to the manufacturers' instructions. Seven of the eight subjects were studied with custom-designed genome-wide array with approximately 180,000 oligonucleotides, manufactured by Agilent Technologies, Inc. (Santa Clara, CA) as previously described [22]. The clinical array is designed by the MGL at BCM with exonby-exon coverage for about 1,700 genes and 700 microRNAs. Confirmatory FISH analyses for $17 \mathrm{q} 25$ deletion were performed using RP11-497H17 and RP11-1182P23. Subject 3 was studied in the Cytogenetics Laboratory at Cincinnati Children's Hospital using both bacterial artificial chromosome (BAC) and single nucleotide polymorphism (SNP) arrays. The SignatureSelect V2 chip containing approximately $4671 \mathrm{BAC}$ clones concentrated in areas of clinical significance, was used for array-CGH. Additional analysis was performed using the Infinium Assay with the Illumina HD Human610-quad BeadChip platform containing approximately 620,900 markers.

\section{Gene ontology, gene expression, protein-protein interaction studies}

To identify the cardiac-specific genes within the terminal region of 17q25, we utilized GeneOntology, Gene Expression, Protein-Protein Interaction networks, haploinsufficiency scores, and miRNA targeting information to score 57 genes encoded within the terminal $2 \mathrm{Mb}$ region of 17q25.3 for relevance to the cardiac phenotype. This approach has successfully been used in our previous studies in identifying novel genes underlying CVMs and epilepsy $[1,23]$.

We analyzed the possibility of CNV loss of each gene contributing to the cardiac phenotype by developing a pathogenicity score, trained using a set of 251 cardiac specific genes that we contextualized via a composite set of annotation resources (Additional file 1: Table S1). To ensure that the constituents of the training set spanned the breadth of genes in which mutations have been observed to cause CVM, we filtered procedures on the Clinical Synopsis data available in Online Mendelian Inheritance in Man (MIM) and manually curated all disorders with any phenotype under the class Cardiovascular. We further expanded upon the training set by identifying additional genes both co-enriched (Fisher's test) with the initial set for the same subset of descriptive terms in the Human Phenotype Ontology [24], and highly similar (Resnik method of calculating semantic similarity) to the initial set [25]. The annotation content employed comprised protein-protein interaction (PPI) data, human tissue expression patterns, microRNA (miRNA) targeting, haploinsufficiency scores [26], known gene-to-disease relationships in the MIM database [27], and phenotype annotations in the Gene Ontology (GO) [28] and Mammalian Phenotype Ontology (MPO) [29]. 
Our scores were determined from the ranked sum of feature scores for each candidate gene. To help ensure that contributions of features were proportionate to their variability and measurement scale, we calculated weighting coefficients from the coefficient of variation of measurements within each feature, most heavily weighing features with the largest amount variability across genes relative to their mean. We also computed the rank of sums of the unweighted candidate feature scores. Two of these features were binary, indicating Yes/No as to whether a candidate gene has been observed in a reported variant as causing heart phenotype in mice (MPO) or in MIM. Another of these features, haploinsufficiency, is itself a previously developed phenotypically aggregate score of developing deleterious phenotypes in the presence of only a single copy of a candidate gene [26]. We also calculated as a feature, a T-statistic scoring candidate gene expression differences between the 10 tissues expressing training genes at the highest levels and the 10 tissues expressing training genes at the lowest levels. In addition, we included as a feature the ontological enrichment of each gene measured against the categories significantly enriched in annotations to the training genes compared to the background using a measure of overlap of GO annotation categories that was determined for each candidate gene. Finally, we calculated as another feature the protein-interaction network communicability of each candidate gene to the training genes normalized to the typical communicability of each gene to the background using the InWeb Protein Interaction Database [30] (Additional file 2: Table S2).

\section{Results}

\section{Subject 1}

Subject 1 was diagnosed with perimembranous ventricular septal defect (VSD) and atrial septal defect (ASD) around one week of age, after she presented with congestive heart failure. She was treated medically with spironolactone, digoxin, and furosemide and was transitioned off her cardiac medications by the age of 2 years. Repeat echocardiogram at 4 years of age revealed closure of the septal defects. Her additional medical problems included strabismus, early feeding difficulties, gastroesophageal reflux, and recurrent otitis media. She was diagnosed with mixed receptive-expressive language disorder, articulation disorder and borderline intellectual functioning at 8 years of age. Her physical examination was remarkable for normal growth parameters of weight of $27.9 \mathrm{~kg}$ (50th-75th percentile), height of $122.4 \mathrm{~cm}$ (10th-25th percentile), and head circumference of $54.0 \mathrm{~cm}$ (50th-90th percentile), facial dysmorphism including upslanting palpebral fissures, midface hypoplasia, downturned corners of the mouth (Fig. 1a), mild scoliosis, and short tapered digits.
The G-banded karyotype analysis and fragile X studies were normal. The array CGH revealed a de novo copy number loss in the subtelomeric region of $17 \mathrm{q} 25.3$ of approximately $1.425 \mathrm{Mb}$ in size, confirmed by FISH analysis. The proximal breakpoint mapped between $77,173,756$ and 77,213,237 (hg18) for this terminal deletion including over 40 RefSeq genes.

\section{Subject 2}

Subject 2 was diagnosed with infra-diaphragmatic total anomalous pulmonary venous return (TAPVR) immediately after birth. He was born at 36 weeks gestation to a 26-year-old female with a history of two prior spontaneous abortions at 6 weeks. The pregnancy was complicated by intrauterine growth restriction. The birth weight was $1734 \mathrm{~g}$ ( $<3 \mathrm{rd}$ percentile), birth length was $43 \mathrm{~cm}$ ( $10^{\text {th }}$ percentile), and head circumference was $30 \mathrm{~cm}\left(5-10^{\text {th }}\right.$ percentile). Other notable features included left eyelid coloboma, tall sloping forehead, smaller right ear in comparison to the left, high-arched palate, triangular shaped face, single transverse palmar crease on the left, rocker bottom feet, and sacral dimple (Fig. 1b). He had a complicated post-operative course requiring extracorporeal membrane oxygenation (ECMO), and passed away on day of life 13. Autopsy revealed left atrial and ventricular hypoplasia, ASD (fenestrated secundum type), VSD, bicuspid aortic valve, patent ductus arteriosus (PDA), immature brain, two accessory spleens, and unilobar left lung.

Karyotype study showed 46,XY,add(17)(q25.3), with additional satellited material of unknown origin attached to the long arm of one chromosome 17 at band $17 \mathrm{q} 25.3$ (Fig. 2a, b). Array CGH revealed a de novo copy number loss of terminal subtelomeric region of $17 q 25.3$ of approximately $1.083 \mathrm{Mb}$ in size, with proximal breakpoint between $77,546,315$ and 77,555,228.

\section{Subject 3}

Subject 3 was diagnosed with coarctation of the aorta (CoA), multiple muscular VSDs, a perimembranous VSD, and unilateral cleft lip in the newborn period. Brain MRI was significant for the presence of ectopic neurohypophysis adjacent to the hypothalamus. He had additional diagnoses of submucus cleft palate, conductive hearing loss, subglottic stenosis, laryngomalacia, gastroesophageal reflux disease with possible intermittent aspiration, and recurrent croup and upper respiratory tract infections. No significant dysmorphic features were noted on evaluation. At 22 months, he underwent bilateral orchiopexy for undescended testicles and complex circumcision revision. He was noted to have mild glanular hypospadias with urethral meatal stenosis. At 29 months, he underwent right nasolacrimal duct stenting. He had fine and gross motor delays and received occupational and physical therapies. He was enrolled in a school for the 


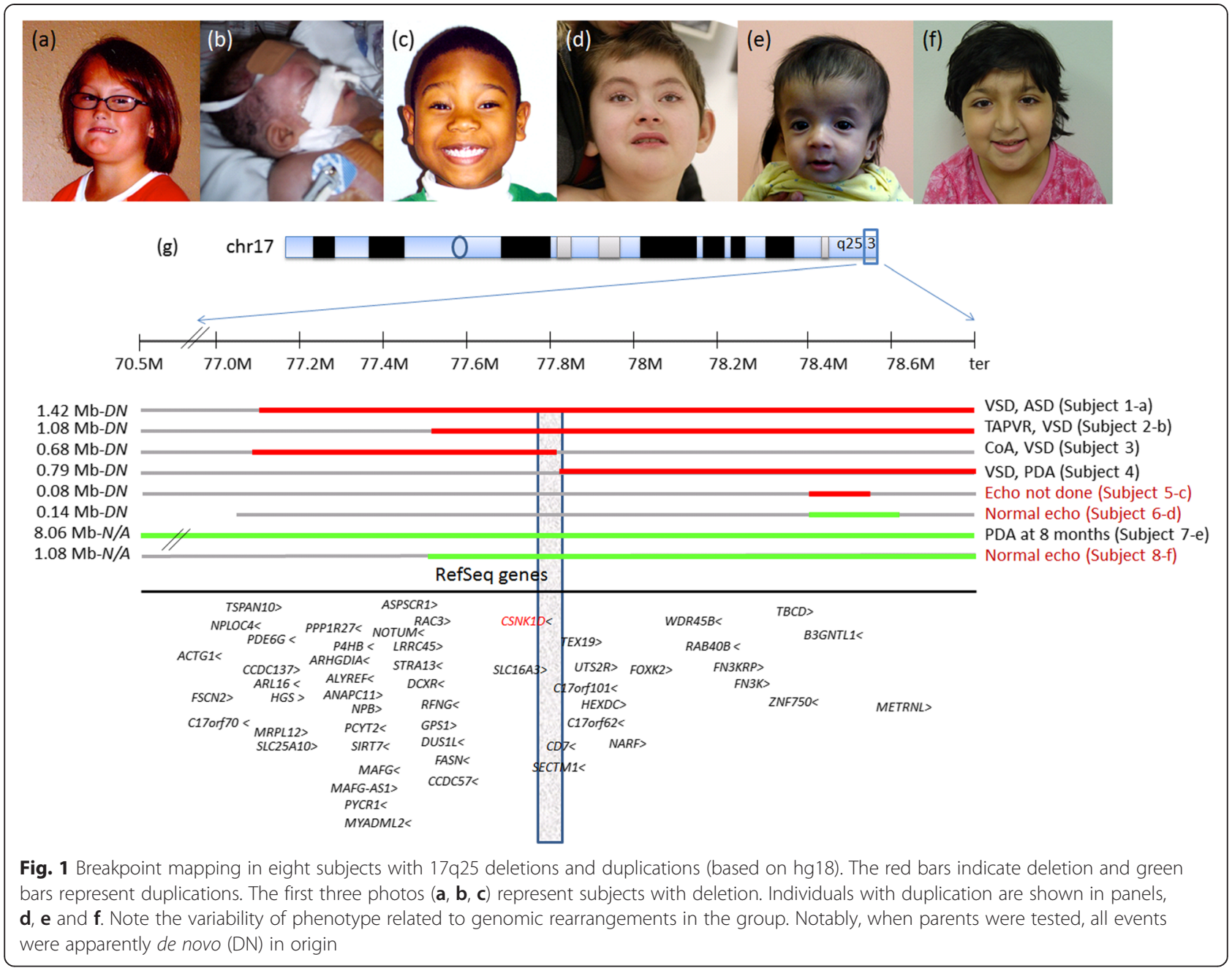

deaf due to severe speech apraxia. At 4 years, 8 months of age, his growth parameters showed a height at the $22^{\text {nd }}$ percentile and weight at the $12^{\text {th }}$ percentile.

Array CGH showed a de novo copy number loss of approximately $684 \mathrm{~kb}$ in size within the $17 \mathrm{q} 25.3$ region $(77,125,528-77,809,659)$, sparing the distal segment.

\section{Subject 4}

Subject 4 was born at 32 weeks gestation with birth weight of $1130 \mathrm{~g}\left(<3^{\text {rd }}\right.$ percentile) and length of $38.7 \mathrm{~cm}$ $\left(10^{\text {th }}\right.$ percentile). The neonatal course was complicated by tracheoesophageal fistula and tethered cord. Echocardiogram showed VSD and PDA. Brain imaging was

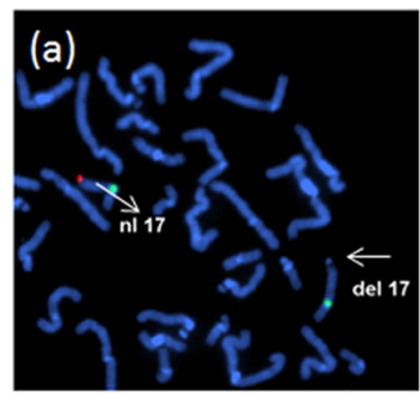

(b)

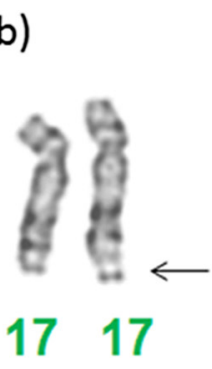

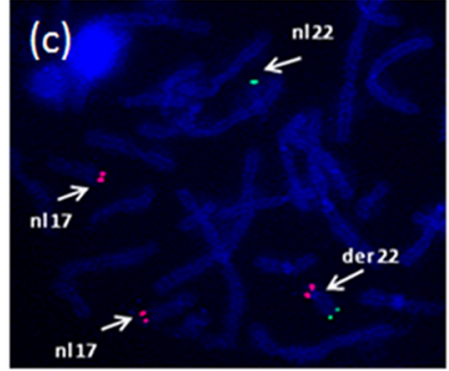

(d)
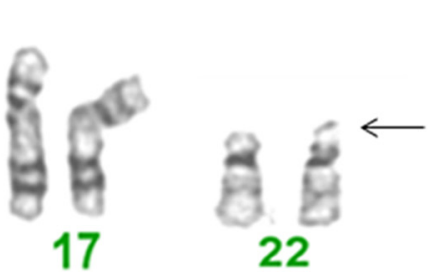

Fig. 2 FISH and partial karyotype images in subject $2(\mathbf{a}, \mathbf{b})$ and subject $7(\mathbf{c}, \mathbf{d})$ are shown. Note the additional satellited material of unknown origin attached to the long arm of one chromosome 17 at band 17q25.3 in subject 2, resulting in de novo copy number loss of the terminal subtelomeric region of $17 q 25.3$ of approximately $1.083 \mathrm{Mb}$ in size. In subject 7, FISH analysis revealed a derivative chromosome 22 with the extra copy of 17qter translocated to the distal short arm of chromosome 22 (c), also observed retrospectively on partial karyotype study 
consistent with agenesis of the corpus callosum. Her development was globally delayed when evaluated at 12 years. She had normal growth parameters with weight of $37.5 \mathrm{~kg}$ (34th percentile), length of $148.5 \mathrm{~cm}$ (44th percentile), and head circumference of $54.6 \mathrm{~cm}$ (50th percentile), sparse eyebrows laterally, bulbous nose, notching of alae nasi bilaterally, long digits, and mild contractures of distal lower extremities.

Array CGH showed a de novo loss of terminal 17q25.3 of approximately $0.80 \mathrm{Mb}$, with the proximal breakpoint mapping between $77,799,839$ and 77,842,711.

\section{Subject 5}

Subject 5 was referred for a developmental evaluation at 30 months of age due to language delay. His cardiac exam was normal, and echocardiogram was not performed. Brain MRI was significant for Chiari I malformation. Formal developmental testing using the Griffith Mental Developmental Scale revealed global developmental delay. There were no significant facial dysmorphisms noted on physical examination (Fig. 1c).

The karyotype analysis and fragile X study were normal. He was found to have a de novo subtelomeric loss on 17q25.3, confirmed by FISH analysis, spanning approximately $0.082 \mathrm{Mb}$, disrupting only two genes, $T B C D$ (Beta tubulin cofactor-D) and B3GNTL1, leaving the distal METRNL gene intact. The proximal breakpoint mapped between $78,452,326$ and $78,454,234$, and the distal breakpoint mapped between 78,536,478 and 78,553,241.

\section{Subject 6}

Subject 6 was born at term via cesarean section for fetal distress. Bilateral congenital cataracts and hypogonadism were noted at birth. His echocardiogram was found to be normal. He was additionally noted to have polysplenia. Brain MRI was significant for thinning of the corpus callosum and cortical dysplasia. At 3 years of age, he was nonverbal and non-ambulatory with global developmental delay. On physical examination, facial dysmorphic features were noted including long narrow face, small upslanting palpebral fissures, a narrow nasal bridge, and slightly prominent ears (Fig. 1d). Contractures were observed throughout, with limited extension of the lower extremities.

Karyotype study was normal. The array CGH revealed a de novo gain in copy number in the subtelomeric region of $17 \mathrm{q} 25.3$ spanning a minimum of $141 \mathrm{~kb}$ involving the TBCD and B3GNTL1 genes, sparing the distal METRNL gene. The proximal breakpoints mapped between 78,457,408 and 78,458,509 and the distal breakpoint mapped between 78,599,991 and 78,623,171.

\section{Subject 7}

Subject 7 was found to have PDA at eight months of age. His additional problems included failure to thrive and dysmorphic facial features. Brain MRI showed mild to moderate cerebral volume loss and minimal cerebellar volume loss. Physical examination at the age of 18 months showed relative macrocephaly, a large anterior fontanel, triangular facies, a prominent forehead, hypertelorism, downslanting palpebral fissures, and low-set ears (Fig. 1e).

The karyotype was $46, \mathrm{XY}$ at 500-band resolution. The array CGH revealed a gain in copy number in the $17 q 25.1-q 25.3$ terminal region, spanning approximately $8.068 \mathrm{Mb}$. The proximal breakpoint mapped between $70,528,836$ and 70,570,936. FISH analysis revealed a derivative chromosome 22 with the third copy of the 17q25.1-q25.3 region translocated to the distal short arm of chromosome 22 (Fig. 2c, d). There was no evidence of a rearrangement in the mother by FISH analysis. Father's sample was unavailable for testing.

\section{Subject 8}

Subject 8 was evaluated at 8 years of age for intellectual disability and microcephaly. She was born with multiple cranial suture synostosis and underwent fronto-orbital advancement in early childhood. Her medical history was also significant for adjustment disorder with mixed anxiety and attention deficit hyperactivity disorder (ADHD). Her echocardiogram was normal. Brain MRI showed minimal patchy frontal encephalomalacia bilaterally. Her ophthalmological exam was unremarkable. Physical examination at 8 years was consistent with microcephaly with head circumference of $48.8 \mathrm{~cm}\left(<5^{\text {th }}\right.$ percentile), normal weight, $31.6 \mathrm{~kg}\left(80^{\text {th }}\right.$ percentile), and height $126.1 \mathrm{~cm}\left(25^{\text {th }}\right.$ percentile). She was noted to have malar hyperplasia, high arched palate, micrognathia, prominent nasal bridge and columella (Fig. 1f). Neurological exam was consistent with mild hypotonia.

The array CGH revealed a gain in copy number in the $17 \mathrm{q} 25.3$ terminal region, spanning approximately $1.08 \mathrm{Mb}$. The proximal breakpoints mapped between 77,546,315 and $77,555,228$. Parents were unavailable for further testing.

\section{Annotation analysis of the region}

Phenotype specific pathogenicity evaluation for annotation features determined relative scores for each gene in the region, with respect to cardiac phenotype. These scores provide an algorithmic basis for prioritizing genes for subsequent functional inquiry. Each feature's variability across genes in the region is a necessary condition for distinguishing among the genes, and the features with the largest coefficients of variation (defined as sd/ mean) across all genes in the region were: known association with heart phenotype(s) in MPO, known causal association(s) between hosted variants and MIM disease and direct interactions [31]. After combining the scores to produce an aggregate result for each gene, we found 
Table 1 Clinical features of eight subjects with non-recurrent deletions and duplications of 17q25

\begin{tabular}{|c|c|c|c|c|c|c|c|c|}
\hline Subject & 1 & 2 & 3 & 4 & 5 & 6 & 7 & 8 \\
\hline Gender & Female & Male & Male & Female & Male & Male & Male & Female \\
\hline Event & Deletion & Deletion & Deletion & Deletion & Deletion & Duplication & Duplication & Duplication \\
\hline Origin & de novo & de novo & de novo & de novo & de novo & de novo & N/A & N/A \\
\hline Minimum Size & $1.42 \mathrm{Mb}$ & $1.08 \mathrm{Mb}$ & $0.68 \mathrm{Mb}$ & $0.796 \mathrm{Mb}$ & $0.08 \mathrm{Mb}$ & $0.14 \mathrm{Mb}$ & $8.06 \mathrm{Mb}$ & $1.08 \mathrm{Mb}$ \\
\hline Echo findings & $\begin{array}{l}\text { Perimembranous VSD } \\
\text { and ASD }\end{array}$ & $\begin{array}{l}\text { TAPVR, VSD, ASD, PDA, } \\
\text { left atrial and } \\
\text { ventricular hypoplasia, } \\
\text { BAV }\end{array}$ & $\begin{array}{l}\text { CoA, multiple } \\
\text { muscular VSDs, } \\
\text { perimembranous } \\
\text { VSD }\end{array}$ & VSD, PDA & Not done & Normal study & $\begin{array}{l}\text { PDA at } 8 \text { months of } \\
\text { age }\end{array}$ & Normal study \\
\hline Cytoband & $17 q 25.3$ & $17 q 25.3$ & $17 q 25.3$ & $17 q 25.3$ & $17 q 25.3$ & $17 q 25.3$ & $17 q 25.1-q 25.3$ & $17 q 25.3$ \\
\hline $\begin{array}{l}\text { Start position } \\
\text { (hg18) }\end{array}$ & $77,173,756-77,213,237$ & $77,546,315-77,555,228$ & $77,125,528$ & $77,799,839-77,842,711$ & $78,452,326-78,454,234$ & $78,457,408-78,458,509$ & $70,528,836-70,570,936$ & $77,546,315-77,555,228$ \\
\hline $\begin{array}{l}\text { End position } \\
\text { (hg18) }\end{array}$ & $78,638,511-78,774,742$ & $78,638,511-78,774,742$ & $77,809,659$ & $78,638,511-78,774,742$ & $78,536,478-78,553,241$ & $78,599,991-78,623,171$ & $78,638,511-78,774,742$ & $78,638,511-78,774,742$ \\
\hline $\begin{array}{l}\text { Age at Last } \\
\text { Examination }\end{array}$ & 8 years & 2 weeks & 5 years, 1 month & 12 years & 2 years, 6 months & 7 years, 5 months & 1 year, 7 months & 8 years \\
\hline Brain Imaging & Not done & $\begin{array}{l}\text { Diffuse and severe } \\
\text { cerebral edema }\end{array}$ & $\begin{array}{l}\text { Ectopic } \\
\text { neurohypophysis, } \\
\text { adjacent to the } \\
\text { hypothalamus }\end{array}$ & $\begin{array}{l}\text { Agenesis of corpus } \\
\text { callosum }\end{array}$ & Chiari I malformation & $\begin{array}{l}\text { Thinning of the } \\
\text { corpus callosum and } \\
\text { cortical dysplasia }\end{array}$ & $\begin{array}{l}\text { Mild to moderate } \\
\text { global volume loss }\end{array}$ & $\begin{array}{l}\text { Minimal patchy frontal } \\
\text { encephalomalacia } \\
\text { bilaterally, linear focus } \\
\text { of increased FLAIR } \\
\text { signal in left periatrial } \\
\text { white matter }\end{array}$ \\
\hline Eye findings & Strabismus & Left eyelid coloboma & $\begin{array}{l}\text { Right nasolacrimal } \\
\text { duct obstruction }\end{array}$ & Unknown & Normal & $\begin{array}{l}\text { Bilateral congenital } \\
\text { cataracts }\end{array}$ & Mild hyperopia & Normal \\
\hline $\begin{array}{l}\text { Muscular/ } \\
\text { skeletal }\end{array}$ & $\begin{array}{l}\text { Normal stature, mild } \\
\text { scoliosis }\end{array}$ & $\begin{array}{l}\text { Rocker-bottom feet } \\
\text { bilaterally }\end{array}$ & Normal stature & $\begin{array}{l}\text { Normal stature, } \\
\text { bilateral calcaneon- } \\
\text { avicular coalition }\end{array}$ & Normal stature & Limb contractures & Short stature & Normal stature \\
\hline $\begin{array}{l}\text { Other } \\
\text { problems }\end{array}$ & & $\begin{array}{l}\text { Polysplenia, unilobar } \\
\text { left lung }\end{array}$ & $\begin{array}{l}\text { Unilateral cleft lip, } \\
\text { submucous cleft } \\
\text { palate, speech } \\
\text { apraxia, moderate } \\
\text { conductive hearing } \\
\text { loss left ear, } \\
\text { subglottic stenosis, } \\
\text { laryngomalacia, } \\
\text { GERD, bilateral } \\
\text { undescended testes, } \\
\text { glanular hypospadias }\end{array}$ & $\begin{array}{l}\text { TE fistula, tethered } \\
\text { cord }\end{array}$ & & $\begin{array}{l}\text { Polysplenia, nocturnal } \\
\text { hypoventilation }\end{array}$ & & $\begin{array}{l}\text { ADHD, psychiatric } \\
\text { disorder }\end{array}$ \\
\hline
\end{tabular}


that ACTG1 and ARHGDIA were the highest scoring genes while MIR3186, OXLD1, MIR6786, MAFG-AS1, MIR6787, OGFOD3, and WDR45B all shared the equally lowest score. Detailed information is provided in Additional file 2: Table S2.

\section{Discussion}

Our study describes eight individuals with deletions and duplications of $17 \mathrm{q} 25$, accentuating the occurrence of congenital cardiac abnormalities in $\sim 60 \%$ of subjects $(5 / 8)$. The craniofacial characteristics and additional congenital anomalies of the described individuals are not typically distinguishing, possibly due to the unique structural variations, occurring in a highly gene-rich region of $17 \mathrm{q} 25$. Neurocognitive deficits were noted in all individuals beyond one year of age, with language delay frequently observed. Brain imaging abnormalities such as cerebral volume loss, white matter changes and corpus callosum abnormalities were noted in 6/8 individuals. Other highly variable non-cardiac anomalies included cleft palate, eyelid coloboma, cataracts, tethered cord, and musculoskeletal abnormalities (Table 1).

Despite a wide phenotypic spectrum observed in this group, the moderate penetrance of CVM is very compelling. The penetrance of cardiac defects is particularly higher in individuals with deletions (4/5) as compared to those with duplications $(1 / 3)$. Of the five individuals with non-recurrent deletions (ranging from $0.08 \mathrm{Mb}-1.42 \mathrm{Mb}$ ), all were de novo with four having distinct cardiac lesions including TAPVR, CoA, and septal defects. The smallest deletion in association with CVM was seen in subject 3 , with the $\sim 0.68 \mathrm{Mb}$ loss encompassing at least 27 RefSeq genes. While four out of five individuals in our cohort with 17q25.3 deletions had CVMs, they did not share a commonly deleted minimal region (Fig. 1). This may suggest that multiple genes within the terminal $\sim 2 \mathrm{Mb}$ of $17 \mathrm{q} 25.3$ are drivers of cardiac patterning in humans. Findings suggestive of abnormal laterality were ob- served in two individuals; subject 2 with polyspenia and unilobar left lung; and subject 6 with polysplenia and normal echocardiogram.

None of the genes within this interval is currently implicated in human CVM, but cardiac expression is observed for several of these genes, including ACTG1, P4HB, ARHGDIA, NPLOC4, MRPL12, DCXR, CSNK1D, SLC16A3 and STRA13 (Additional file 2: Table S2).

To refine cardiac-specific genes within this locus, we used a bioinformatics approach using Gene Expression, GeneOntology, Protein-Protein Interaction networks, haploinsufficiency data, and MPO, and utilized a set of over 250 cardiac-specific genes to assign pathogenicity score to the 57 genes within the terminal $2 \mathrm{Mb}$ of $17 \mathrm{q} 25$ region. Based on the complex computation analyses, high priority candidate genes shared by at least 3 individuals with CVMs included ARHGDIA, MAFG, CSNK1D, RAC3, HGS, and SIRT7 (Additional file 2: Table S2). Other genes such as NPLOC4, SLC16A3, and $U T S 2 R$ are also important considerations. It is notable that within this region, none of the deletions include ACTG1, which is implicated in Baraitser-Winter syndrome 2, an autosomal dominant disorder characterized by neuronal migration defect, distinctive face, and cardiac defects including bicuspid valve, VSD and PDA [32, 33] (Table 2).

ARHGDIA, encoding Rho GDP dissociation inhibitor $\alpha$ (RhoGDI $\alpha$ ) was found to have a high pathogenicity score in our study. Involved in cardiac specific inhibition of Rho family protein, this gene is deleted or duplicated in 3/5 individuals with CVMs. While increased expression of RhoGDI $\alpha$ causes defective heart looping, poor trabeculation, impaired chamber demarcation, absence of endocardial cushion and hypocellularity [34], targeted inactivation of Arhgdia has been shown to cause severe proteinuria and nephrotic syndrome in mice [35]. Homozygous mutations in ARHGDIA have now been shown to cause nephrotic syndrome in several families

Table 2 MIM annotated genes with known phenotype within the terminal 2.0 Mb segment of 17q25.3

\begin{tabular}{|c|c|c|c|c|}
\hline Gene & Annotated MIM entries & MIM IDs & Inheritance & $\begin{array}{l}\text { Heterozygous deletion and } \\
\text { duplication in subjects }\end{array}$ \\
\hline ACTG1 & Baraitser-Winter syndrome 2; Deafness, autosomal dominant 20/26 & $604717 ; 614583$ & $A D$ & 7 \\
\hline FSCN2 & Retinitis pigmentosa 30 & 607921 & $A D$ & 7 \\
\hline PDE6G & Retinitis pigmentosa 57 & 613582 & AR & $1,3,7$ \\
\hline ARHGDIA & Nephrotic syndrome, type 8 & 615244 & AR & $1,3,7$ \\
\hline PYCR1 & Cutis laxa, autosomal recessive, type IIB; Cutis laxa, autosomal recessive, type IIIB & $612940 ; 614438$ & $A R$ & $1,3,7$ \\
\hline ASPSCR1 & Alveolar soft-part sarcoma & 606243 & & $1,2,3,7,8$ \\
\hline$D C X R$ & Pentosuria & 260800 & $A R$ & $1,2,3,7,8$ \\
\hline CSNK1D & Advanced sleep-phase syndrome, familial, 2 & 615224 & $A D$ & $1,2,3,7,8$ \\
\hline ZNF750 & Seborrhea-like dermatitis with psoriasiform elements & 610227 & $A D$ & $1,2,4,7,8$ \\
\hline
\end{tabular}


[36, 37], consistent with the animal studies. This suggests that this gene is less likely to explain CVM in individuals with deletions, but may contribute to CVM when duplicated. It is interesting to note that the two subjects with duplications distal to this gene (subjects 6 and 8) had normal echocardiogram studies. SIRT7, a member of the sirtuin family of genes, is another candidate gene with a relatively high pathogenicity score affected in 3/5 subjects with CVMs. Sirt7-deficient mice develop progressive heart hypertrophy with an increased number of apoptotic cells in myocardium [38]. Sirt7deficient cardiomyocytes show a reduced resistance to oxidative stress, indicating an important role of Sirt7 in the regulation of stress responses and cell death in the heart [38]. HGS, encoding hepatocyte growth factor-regulated tyrosine kinase substrate, is also a good candidate gene inferred from our bioinformatics analysis and involved in $3 / 5$ subjects. HGS is known to transduce BMP signaling for proper embryonic development [39], and its disruption causes early embryonic lethality after gastrulation [40]. Another important candidate gene from our study affected in $4 / 5$ subjects is UTS2R, encoding urotensin II and known to have potent vasoconstrictor effects. UTS2R has been shown to have a potential link to cardiac remodeling such as hypertrophy [41]. However, its role in structural heart defects remains to be elucidated. CSNK1D encodes an isoform of casein kinase I, a serine/ threonine-specific protein kinase with important function in ciliogenesis [42]. Homozygous mice die within days of birth [43]. This gene is deleted in 3/5 subjects with CVMs, duplicated in the fourth, and could be either partially deleted or immediately flanking the deletion observed in subject 4 with VSD and PDA. The gene scores in the top $12 \%$ in the pathogenicity score from our bioinformatics analysis and remains an excellent candidate gene for congenital cardiac defects observed in this study.

\section{Conclusion}

The ubiquitous use of next generation sequencing technology in individuals with CVMs may ultimately identify causative gene(s) within this important CNV. Several of the genes within the 17q25.3 interval have significant number of predicted loss of function mutations in the Exome Aggregation Consortium (ExAC) database (Additional file 3: Table S3). Our study highlights a comprehensive phenotypic spectrum associated with rarely described $17 \mathrm{q} 25$ telomeric deletions and duplications and underscores the region as a novel cardiac-susceptibility locus.

\section{Availability of supporting data}

The data set supporting the results of this article is included within the article and its additional files.

\section{Additional files}

Additional file 1: Table S1. List of 251 genes linked to cardiac phenotype.

Additional file 2: Table S2. Pathogenicity score (Equally_Weighted_Rank) of the genes within the 17q25.3 region, trained using a known set of over 200 genes from Table 1.

Additional file 3: Table S3. Number of deleterious variants in genes within $17 q 25.3$ from the EXAC dataset.

\section{Competing interests}

The authors declare that they have no competing interests.

\section{Authors' contributions}

FJP, LCB, and SRL wrote the manuscript. FJP, SRL, TPB, CHWM, CB, AIAF, MA, and SMW recruited and/or evaluated patients. PM, and EA assisted in patient evaluation. RAJ and CS carried out the bioinformatics analysis. AP, CB, SWC, $W B, F X$, and SRL played a role in the analysis of molecular genetic studies. JAR and JWB assisted in the design of the study and analysis of the data. All authors read and approved the final manuscript.

\section{Acknowledgements}

We would like to thank our patients for participating in this study. Support for this work was provided by RO1-HL091771 to John. W. Belmont and Seema R. Lalani, March of Dimes grant to Stephanie M. Ware and Seema R. Lalani. Frank J. Probst holds a Career Award for Medical Scientists from the Burroughs Wellcome Fund. Lindsay C. Burrage was supported by the Medical Genetics Research Fellowship Program NIH/NIGMS NIH T32 GM07526.

\section{Author details}

'Department of Molecular and Human Genetics, Baylor College of Medicine, One Baylor Plaza, MS BCM225, Houston, TX, USA. '2Department of Neurology, Memorial Hermann Texas Medical Center, Houston, TX, USA. ${ }^{3}$ Genetic Center, Children's Hospital Medical Center Of Akron, Akron, OH, USA. ${ }^{4}$ Department of Developmental Pediatrics, Texas Children's Hospital, Houston, TX, USA.

${ }^{5}$ Departments of Pediatrics and Medical and Molecular Genetics, Indiana University School of Medicine, Indianapolis, IN, USA.

Received: 28 March 2015 Accepted: 2 June 2015 Published online: 14 June 2015

\section{References}

1. Lalani SR, Shaw C, Wang X, Patel A, Patterson LW, Kolodziejska K, et al. Rare DNA copy number variants in cardiovascular malformations with extracardiac abnormalities. Eur J Hum Genet. 2013;21(2):173-81.

2. Greenway SC, Pereira AC, Lin JC, DePalma SR, Israel SJ, Mesquita SM, et al. De novo copy number variants identify new genes and loci in isolated sporadic tetralogy of Fallot. Nat Genet. 2009;41(8):931-5.

3. Fakhro KA, Choi M, Ware SM, Belmont JW, Towbin JA, Lifton RP, et al. Rare copy number variations in congenital heart disease patients identify unique genes in left-right patterning. Proc Natl Acad Sci U S A. 2011;108(7):2915-20.

4. lascone M, Ciccone R, Galletti L, Marchetti D, Seddio F, Lincesso AR, et al. Identification of de novo mutations and rare variants in hypoplastic left heart syndrome. Clin Genet. 2012;81(6):542-54.

5. Hitz MP, Lemieux-Perreault LP, Marshall C, Feroz-Zada Y, Davies R, Yang SW, et al. Rare copy number variants contribute to congenital left-sided heart disease. PLoS Genet. 2012;8(9), e1002903.

6. Mefford HC, Sharp AJ, Baker C, Itsara A, Jiang Z, Buysse K, et al. Recurrent rearrangements of chromosome 1q21.1 and variable pediatric phenotypes. N Engl J Med. 2008;359(16):1685-99.

7. Dolcetti A, Silversides CK, Marshall CR, Lionel AC, Stavropoulos DJ, Scherer SW, et al. 1q21.1 Microduplication expression in adults. Genet Med. 2013;15(4):282-9.

8. Silversides CK, Lionel AC, Costain G, Merico D, Migita O, Liu B, et al. Rare copy number variations in adults with tetralogy of Fallot implicate novel risk gene pathways. PLoS Genet. 2012;8(8), e1002843.

9. Ben-Shachar S, Ou Z, Shaw CA, Belmont JW, Patel MS, Hummel M, et al. 22q11.2 distal deletion: a recurrent genomic disorder distinct from DiGeorge syndrome and velocardiofacial syndrome. Am J Hum Genet. 2008;82(1):214-21. 
10. Fagerberg CR, Graakjaer J, Heinl UD, Ousager LB, Dreyer I, Kirchhoff M, et al. Heart defects and other features of the 22q11 distal deletion syndrome. Eur J Med Genet. 2013;56(2):98-107.

11. Lukusa T, Fryns JP. Pure de novo 17q25.3 micro duplication characterized by micro array CGH in a dysmorphic infant with growth retardation, developmental delay and distal arthrogryposis. Genet Couns. 2010;21(1):25-34.

12. Christofolini DM, de Paula Ramos MA, Kulikowski LD, da Silva Bellucco FT, Belangero SI, Brunoni D, et al. Subtelomeric rearrangements and copy number variations in people with intellectual disabilities. J Intellect Disabil Res. 2010;54(10):938-42.

13. Hackmann K, Stadler A, Schallner J, Franke K, Gerlach EM, Schrock E, et al. Severe intellectual disability, West syndrome, Dandy-Walker malformation, and syndactyly in a patient with partial tetrasomy 17q25.3. Am J Med Genet A. 2013;161A(12):3144-9.

14. Poulton CJ, Schot R, Seufert K, Lequin MH, Accogli A, Annunzio GD, et al. Severe presentation of WDR62 mutation: is there a role for modifying genetic factors? Am J Med Genet A. 2014;164A(9):2161-71.

15. Brisset S, Kasakyan S, L'Hermine AC, Mairovitz V, Gautier E, Aubry MC, et al. De novo monosomy 9p24.3-pter and trisomy 17q24.3-qter characterised by microarray comparative genomic hybridisation in a fetus with an increased nuchal translucency. Prenat Diagn. 2006:26(3):206-13.

16. Fryns JP, Parloir C, Van den Berghe H. Partial trisomy 17q. Karyotype: 46, XY, der(21), t(17;21)(q22;p13). Hum Genet. 1979;49(3):361-4

17. Marques F, Heredia R, de Oliveira C, Cardoso MT, Mazzeu J, Pogue R. Partial trisomy $17 q$ and partial monosomy $20 q$ in a boy with craniosynostosis. Am J Med Genet A. 2015;167A(2):412-6.

18. McCann E, Sweeney E, Sills J, May P, Smith S. Pfeiffer-type cardiocranial syndrome: a patient with features of this condition and with an unbalanced subtelomeric rearrangement involving chromosomes $1 p$ and $17 \mathrm{q}$. Clin Dysmorphol. 2006;15(2):81-4

19. Sarri C, Gyftodimou J, Avramopoulos D, Grigoriadou M, Pedersen W, Pandelia E, et al. Partial trisomy 17q22-qter and partial monosomy Xq27qter in a girl with a de novo unbalanced translocation due to a postzygotic error: case report and review of the literature on partial trisomy 17qter. Am J Med Genet. 1997;70(1):87-94.

20. Velagaleti GV, Jalal SM, Michaelis RC, Rowe TF, Nichols JR, Lockhart LH. Molecular cytogenetic characterization of a de novo unbalanced translocation leading to trisomy $17 q 25 \rightarrow$ qter and monosomy 18 p11.3 $\rightarrow$ pter in a girl with dysmorphic features. Clin Dysmorphol. 2003;12(1):29-33.

21. Bacino CA, Kashork CD, Davino NA, Shaffer LG. Detection of a cryptic translocation in a family with mental retardation using FISH and telomere region-specific probes. Am J Med Genet. 2000;92(4):250-5.

22. Boone PM, Bacino CA, Shaw CA, Eng PA, Hixson PM, Pursley AN, et al. Detection of clinically relevant exonic copy-number changes by array $\mathrm{CGH}$. Hum Mutat. 2010;31(12):1326-42.

23. Campbell IM, Rao M, Arredondo SD, Lalani SR, Xia Z, Kang SH, et al. Fusion of large-scale genomic knowledge and frequency data computationally prioritizes variants in epilepsy. PLoS Genet. 2013;9(9), e1003797.

24. Robinson PN, Kohler S, Bauer S, Seelow D, Horn D, Mundlos S. The Human Phenotype Ontology: a tool for annotating and analyzing human hereditary disease. Am J Hum Genet. 2008:83(5):610-5.

25. Kohler S, Schulz MH, Krawitz P, Bauer S, Dolken S, Ott CE, et al. Clinical diagnostics in human genetics with semantic similarity searches in ontologies. Am J Hum Genet. 2009;85(4):457-64.

26. Huang N, Lee I, Marcotte EM, Hurles ME. Characterising and predicting haploinsufficiency in the human genome. PLoS Genet. 2010;6(10), e1001154.

27. Hamosh A, Scott AF, Amberger JS, Bocchini CA, McKusick VA. Online Mendelian Inheritance in Man (OMIM), a knowledgebase of human genes and genetic disorders. Nucleic Acids Res. 2005;33(Database issue):D514-7.

28. Ashburner M, Ball CA, Blake JA, Botstein D, Butler H, Cherry JM, et al. Gene ontology: tool for the unification of biology. The Gene Ontology Consortium. Nat Genet. 2000;25(1):25-9.

29. Smith CL, Eppig JT. The mammalian phenotype ontology: enabling robust annotation and comparative analysis. Wiley Interdiscip Rev Syst Biol Med. 2009;1(3):390-9.

30. Lage K, Mollgard K, Greenway S, Wakimoto H, Gorham JM, Workman CT, et al. Dissecting spatio-temporal protein networks driving human heart development and related disorders. Mol Syst Biol. 2010;6:381.

31. Wu J, Vallenius T, Ovaska K, Westermarck J, Makela TP, Hautaniemi S. Integrated network analysis platform for protein-protein interactions. Nat Methods. 2009;6(1):75-7.
32. Riviere JB, van Bon BW, Hoischen A, Kholmanskikh SS, O'Roak BJ, Gilissen C, et al. De novo mutations in the actin genes ACTB and ACTG1 cause Baraitser-Winter syndrome. Nat Genet. 2012:44(4):440-4. 4

33. Verloes A, Di Donato N, Masliah-Planchon J, Jongmans M, Abdul-Raman OA, Albrecht B, et al. Baraitser-Winter cerebrofrontofacial syndrome: delineation of the spectrum in 42 cases. Eur J Hum Genet. 2014;23(3):292-301.

34. Wei L, Imanaka-Yoshida K, Wang L, Zhan S, Schneider MD, DeMayo FJ, et al. Inhibition of Rho family GTPases by Rho GDP dissociation inhibitor disrupts cardiac morphogenesis and inhibits cardiomyocyte proliferation. Development. 2002;129(7):1705-14.

35. Togawa A, Miyoshi J, Ishizaki H, Tanaka M, Takakura A, Nishioka H, et al Progressive impairment of kidneys and reproductive organs in mice lacking Rho GDlalpha. Oncogene. 1999;18(39):5373-80.

36. Gee HY, Saisawat P, Ashraf S, Hurd TW, Vega-Warner V, Fang H, et al. ARHGDIA mutations cause nephrotic syndrome via defective RHO GTPase signaling. J Clin Invest. 2013;123(8):3243-53.

37. Gupta IR, Baldwin C, Auguste D, Ha KC, El Andalousi J, Fahiminiya S, et al. ARHGDIA: a novel gene implicated in nephrotic syndrome. J Med Genet. 2013;50(5):330-8.

38. Vakhrusheva O, Smolka C, Gajawada P, Kostin S, Boettger T, Kubin T, et al. Sirt7 increases stress resistance of cardiomyocytes and prevents apoptosis and inflammatory cardiomyopathy in mice. Circ Res. 2008;102(6):703-10.

39. Miura S, Mishina Y. Hepatocyte growth factor-regulated tyrosine kinase substrate (Hgs) is involved in BMP signaling through phosphorylation of SMADS and TAK1 in early mouse embryo. Dev Dyn. 2011;240(11):2474-81.

40. Komada M, Soriano P. Hrs, a FYV finger protein localized to early endosomes, is implicated in vesicular traffic and required for ventral folding morphogenesis. Genes Dev. 1999;13(11):1475-85.

41. Desai N, Sajjad J, Frishman WH. Urotensin II: a new pharmacologic target in the treatment of cardiovascular disease. Cardiol Rev. 2008;16(3):142-53.

42. Greer YE, Westlake CJ, Gao B, Bharti K, Shiba Y, Xavier CP, et al. Casein kinase 1 delta functions at the centrosome and Golgi to promote ciliogenesis. Mol Biol Cell. 2014;25(10):1629-40

43. Xu Y, Padiath QS, Shapiro RE, Jones CR, Wu SC, Saigoh N, et al. Functional consequences of a CKIdelta mutation causing familial advanced sleep phase syndrome. Nature. 2005;434(7033):640-4.

\section{Submit your next manuscript to BioMed Central and take full advantage of:}

- Convenient online submission

- Thorough peer review

- No space constraints or color figure charges

- Immediate publication on acceptance

- Inclusion in PubMed, CAS, Scopus and Google Scholar

- Research which is freely available for redistribution 